\title{
OS IDOSOS EM UM CONTEXTO DE TRABALHO E DE DISPOSIÇÕES RENOVADAS
}

\author{
Iracema Brandão Guimarães ${ }^{1}$
}

\begin{abstract}
RESUMO
0 presente artigo parte do suposto de que a participação das pessoas idosas nas atividades econômicas tende a ser mais elevada em nosso país e, desse modo, busca conhecer alguns dos fatores que ilustram essa participação. Através da análise, o artigo busca identificar a existência de disposições renovadas entre esses trabalhadores admitindo que isto explicaria em grande parte o seu acesso crescente ao mercado de trabalho na atualidade. Para tanto, utiliza-se de diferentes fontes de dados estatísticos sobre a população e o mercado de trabalho e busca identificar, em grandes linhas, as transformações da economia que determinam a sua dinâmica atual, demonstrando que existe maior concentração dos trabalhadores idosos atuando como autônomos e pequenos empregadores, geralmente, em atividades que se caracterizam por relativa autonomia e diferenciações nas jornadas de trabalho.
\end{abstract}

Palavras Chave: Idade. Trabalho. Mercado. Autonomia.

\section{THE ELDERLY IN A CONTEXT OF WORK AND RENEWED DISPOSITIONS}

\begin{abstract}
The present article starts from the assumption that the participation of elderly people in economical activities tends to be higher in our country; therefore, its objective is to search for some of the factors that illustrate this participation. The article tries to identify the existence of renewed morale among these professionals, admitting that it would largely explain their increasing access to the job market today. In order to do that, different sources of statistical data about the population and the job-market are used to identify, in general terms, the

\footnotetext{
${ }^{1}$ Professora do Departamento de Sociologia/FFCH, Universidade Federal da Bahia, Brasil, e Pesquisadora
} do CNPQ, 2012. iracema.brandao@hotmail.com
\end{abstract}


transformations occurred in the economy which determine its current dynamics. This shows that there is a higher concentration of elderly professionals working as self-employed people or small business owners, generally, in activities which are relatively autonomous and allow flexible work hours.

Keywords: Age. Work. Job Market. Autonomy.

\section{INTRODUÇÃO}

O

atual realinhamento das tendências demográficas vem sendo reconhecido como um importante acontecimento que tem, entre as suas conseqüências, um processo de envelhecimento populacional sem precedentes, e que é paralelo ao de diferentes países. No Brasil, desde a década de 1960, essa tendência está associada a uma desaceleração do crescimento populacional que se torna evidente a partir dos dados sobre 0 acréscimo populacional revelado nos últimos censos demográficos: 23,0 milhões de pessoas (15,6\%) entre 1991/2000; e 21,0 milhões de pessoas (12,3\%) entre 2000/2010. Apesar da impressionante grandeza dos números, a taxa média geométrica de crescimento anual brasileira se desacelerou: 2,99\% ao ano, entre 1950 e 60; para 1,17\% entre 2000 e 2010 (IBGE, 2010), como resultado do jogo entre o declínio da fecundidade das mulheres brasileiras e os índices de mortalidade, implicando em uma alteração da composição etária - ou seja, o crescimento relativamente elevado da população idosa em relação às mais jovens - e um processo de envelhecimento populacional que está em foco.

Embora paralelo a diferentes países, tal processo tende a ser mais lento entre aqueles considerados em desenvolvimento, conforme observam Queiroz et al. (2007, p. 344). 0 mesmo se poderia dizer em relação a outro paralelo que se refere à participação de pessoas idosas nas atividades econômicas, considerada como mais elevada no Brasil do que em outros países. Esse último fenômeno pode encobrir aspectos (positivos e negativos) merecedores de atenção, no que se refere à demanda do mercado de trabalho em consequiência das novas determinações da reestruturação produtiva, de flexibilização do trabalho e de suas diferentes nuances; e também à oferta da força de trabalho, mediante os atributos considerados sociais dessa oferta (OFFE, 1989), especialmente a idade e o sexo.

Tais atributos se inscrevem nas relações de geração e de gênero e têm, no primeiro caso, uma correspondência com o envelhecimento populacional com implicações amplas e variadas que abrangem desde as mudanças nas disposições dos agentes envolvidos, através de novas práticas e representações subjetivas daqueles que se encontram na última fase da vida, até a sua participação em uma família também 
renovada, e a ampliação da demanda por políticas públicas e por distribuição de recursos na sociedade. Depreende-se, portanto, que a maior expectativa de vida contribui para um aumento do acesso ao consumo, para a concretização de planos adiados como o acesso ou o retorno à educação - e também, para a permanência ou reingresso no mercado de trabalho.

Neste caso, o trabalho após os 60 anos pressupõe que se está em condições de dispor da força de trabalho, entendendo-se nesse primeiro plano tanto as condições de saúde física e mental, como as disposições práticas (BOURDIEU, 1994, p. 18) que incluem o trabalho, a família, a sociabilidade. Entendemos que no contexto atual de tantas mudanças, dispor da força de trabalho pode abranger, em um sentido mais amplo, não tanto a permanência, ou reinserção como empregado (vender a força de trabalho), mas a permanência, ou reinserção como trabalhador autônomo, e mesmo como pequeno empregador, já que em ambas os casos se trata de um mundo de trabalho heterogêneo que parece abrigar o maior contingente dos velhos trabalhadores, como os números indicam.

Essa é a questão central que buscamos desenvolver no presente artigo, atentando para 0 fato de que o prolongamento da vida ativa pareceria contrariar a tão esperada fase do descanso, da aposentadoria, ao tempo em que muitas vezes pode contribuir para dar um novo rumo ao trabalhador da terceira idade (SANTOS et al., 2007). 0 presente trabalho se propõe a examinar alguns aspectos da última questão indicada acima, considerando as duas ordens de fatores que contribuem para tanto: o ponto de vista da oferta de força de trabalho, já que o prolongamento da vida economicamente ativa implica em exercer pressão sobre o mercado de trabalho em busca de oportunidades, implicando também em capacidade de se atualizar e se manter nas atividades já exercidas, ou renovadas; e o ponto de vista das novas dimensões da demanda no mercado de trabalho, como efeito de um jogo entre as forças econômicas.

Seja como opção, ou como necessidade, a convergência entre o prolongamento do tempo de vida e da atividade produtiva, representa hoje uma realidade que passa a fazer parte dos planos individuais, incorrendo na contribuição familiar e na própria sobrevivência individual, ao tempo em que representa alternativas para empresas e 0 mundo dos negócios, ainda que muitas vezes sob o manto da terceirização e da precarização do trabalho.

0 presente artigo busca contribuir para a importante reflexão que se encontra implícita nas constatações dos dados estatísticos de que a participação dos mais velhos nas atividades econômicas é relativamente elevada em nosso país. 


\section{O TRABALHO APÓS OS 50 E OS 60 ANOS - O QUE DIZEM OS NÚMEROS.}

Em termos comparativos, o envelhecimento populacional é considerado por Queiroz et al. (2007, p. 344) como sendo mais lento entre aqueles países em desenvolvimento, nos quais a idade média da população pode chegar a 36 anos em 2050, enquanto nos países desenvolvidos deve chegar a 45 anos no mesmo período. No primeiro caso, considera-se a possibilidade de uma aceleração do envelhecimento no plano demográfico, em função do declínio atualmente mais rápido da fecundidade e da mortalidade nestes países, segundo os autores citados:

[como] resultado da manutenção por um período de tempo razoavelmente longo das taxas de crescimento da população idosa superiores às da população mais jovem, implicando em mudança nos pesos dos diversos grupos etários no total da população (QUEIROZ et al., 2007, p. 344).

Isso pode ser observado através do alargamento do topo da pirâmide etária que reflete o seguinte aumento proporcional da população com 65 anos ou mais de idade 4,8\% em 1991, passando a 5,9\% em 2000, e chegando a 7,4\% em 2010 (IBGE, 2010).2 Refletindo as diferenças demográficas entre as regiões, os dados do censo de 2010 (IBGE, 2010) indicam que o processo não é uniforme e o envelhecimento tende a ser menor na região Norte, onde a proporção de idosos na população passou de 3,0\% em 1991, para $3,6 \%$ em 2000, e 4,6\% em 2010; um pouco maior no Nordeste, onde a proporção de idosos na população passou de 5,1\% em 1991 a 5,8\% em 2000, e 7,2\% em 2010, enquanto as Regiões Sudeste e Sul, segundo a mesma fonte, apresentam evoluções semelhantes da estrutura etária, mantendo-se como as duas regiões mais envelhecidas do País - as duas regiões tinham em 2010 um contingente de idosos com 65 anos ou mais de $8,1 \%$ (IBGE, 2010).

Quadro 1 - Número de pessoas por faixa etária

\begin{tabular}{|l|l|l|l|l|}
\hline $60 \mathrm{a}$ 64 anos & 65 a 69 anos & 70 a 74 anos & 75 a 79 anos & 80 anos ou mais \\
\hline 6.509 .119 & 4.840 .810 & 3.741 .637 & 2.563 .448 & 2.935 .585 \\
\hline
\end{tabular}

Fonte: IBGE, 2010.

\footnotetext{
${ }^{2}$ Existe discussão sobre a conceituação de população idosa, ou seja, qual a faixa de idade a partir da qual um segmento populacional pode ser considerado idoso. Concordamos com o argumento de que "a escolha de 60 anos como o início do intervalo prende-se ao fato de que é esse o intervalo considerado pela Política Nacional do Idoso." (CAMARANO; MEDEIROS, 1999, p. 4-8).
} 
A diferenciação interna no grupo dos idosos é significativa, observando-se que a faixa de 80 anos e mais apresentou o maior crescimento, confirmando tendência já observada em estudos anteriores (CAMARANO, 2001). Destaca-se, nesse caso, uma sobrevivência maior entre as mulheres, cuja presença numérica é mais expressiva do que a dos homens nesta última fase da vida. A expectativa de vida que era de 68,6 anos para ambos os sexos, segundo o censo de 2000, indicava uma significativa diferença: 64,8 anos para os homens e 72,6 anos para as mulheres, atribuindo-se tal diferença às explicações demográficas de sobre-mortalidade masculina, especialmente, aos altos índices de mortalidade por causas externas entre homens jovens e adultos, embora também se deva atentar para outros aspectos que influenciam a longevidade feminina, como os cuidados com a saúde, e outros fatores mais subjetivos. Os dados recentes do IBGE apontam para o crescimento diferencial da esperança de vida por sexo como segue:

Para os homens, este valor passou de 15,17 para 19,55 anos e para as mulheres de 17,63 para 22,83 anos. Neste caso, entre 1980 - 2009, a vida média masculina passaria de 75,17 para 79,55 anos, e a feminina, dos 77,63 para 82,83 anos (IBGE, 2009).

Em relação à participação nas atividades econômicas, esta é considerada mais elevada no Brasil em termos comparativos. Em seu estudo, Camarano (2001) registrou que essa participação era alta em relação aos padrões internacionais, relacionando-a a uma particularidade do mercado de trabalho brasileiro que é a inserção do aposentado. Estudo do Departamento Intersindical de Estatísticas e Estudos Sócio-Econômicos (BRASIL, 2001, p. 255) também confirmava que o alongamento do tempo trabalhado, do ponto de vista dos postulantes à aposentadoria, "colocava-se na contramão da tendência internacional que era de diminuição do período de atividade", devido a duas diretrizes políticas: como uma forma de distribuição de renda gerida pelo Estado; e como política para facilitar o acesso das novas gerações ao emprego nos países considerados desenvolvidos.

Isto colocaria o problema da ampliação da oferta da força de trabalho que se expressa em exercer "pressão" sobre o mercado, uma questão que foi observada, por exemplo, por Bruschini em relação a outro segmento, ao enfatizar a intensidade e constância do crescimento do trabalho feminino ocorrido especialmente no período 8595, "quando as mulheres desempenharam papel muito mais relevante que os homens no crescimento da PEA (População Economicamente Ativa), passando a representar 40 $\%$ da força de trabalho brasileira" (BRUSCHINI, 2000, p. 16). Já no caso dos trabalhadores mais velhos, observa-se que em estudo apresentado com base em dados coletados mensalmente entre 2002 e 2006, a Pesquisa Mensal de Emprego/PME demonstra que, neste último ano, as pessoas que se encontravam acima dos 50 anos já 
representavam $18,1 \%$ do total das pessoas ocupadas e residentes no conjunto das seis regiões metropolitanas brasileiras (IBGE, 2012).

Este segmento (acima dos 50 anos), segundo a mesma fonte, se destacou por apresentar um aumento de sua participação no total da população ocupada, da ordem de 2,7 pontos percentuais, o qual se mostrou mais elevado na Região Metropolitana do Rio de Janeiro, onde existe uma maior participação de pessoas mais velhas e ocupadas $(22,3 \%)$ (IBGE, 2012).

Outras tendências destacadas no estudo citado foram:

a) Taxa de atividade - Considerando a faixa mais restrita, acima de 60 anos (idosos), esta representava pouco mais da metade das pessoas acima dos 50 anos ou mais de idade. Nesta faixa etária, 19,3\% fazia parte da população economicamente ativa, entre os quais, como se viu acima, 18,8\% estavam ocupados e 0,5\% desocupados.

b) Posição na ocupação - Sabe-se que no total de ocupados, a categoria de empregados com carteira de trabalho assinada no setor privado (formal) corresponde à maior parte da força de trabalho brasileira (41,7\% em 2006), dos quais 24,1 encontravam-se acima de 50 anos. Entretanto, a categoria que mais favoreceu os trabalhadores nesta faixa etária foi o "trabalho por conta própria" (32,7\% em 2006).

c) Trabalhadores mais velhos: 0 "trabalho por conta própria" representava 24,8\% dos idosos ocupados no ano de 2002 tendo aumentado para 31,0\%, em 2006, provavelmente expressando a própria expansão da atividade informal no seu conjunto. Isto significou que essa atividade absorveu quase $1 / 3$ dos idosos ocupados, uma questão central que merecerá comentários mais adiante, assim como a categoria de militares e funcionários públicos aparece em seguida, apresentando aumento na participação dos mais velhos, da ordem de 18,6\% (em 2002) para 23,3\% (em 2006). Além disso, as pessoas acima dos 50 anos representavam 29,5\% do total de empregadores em 2002, aumentando para 33,6\% em 2006.

\section{O TRABALHO APÓS OS 50 E 60 ANOS - O QUE DIZ O MERCADO}

Entre os fatores determinantes do acesso das pessoas mais velhas ao trabalho merece atenção a demanda do mercado de trabalho no que se refere às novas características da reestruturação produtiva, e da flexibilização do trabalho com suas diferentes nuances. Em termos gerais, admite-se que houve um conjunto de fatores que resultaram na ruptura de um padrão de desenvolvimento estabelecido a partir do pós- 
guerra e perdurando nas décadas de 1960 e 1970 com intensos efeitos nos anos de 1980. Mattoso (1994, p. 14), por exemplo, admite que: "[...] houve uma Terceira Revolução Industrial (ligada ao uso mais intenso da informática) e uma nova configuração do capitalismo mundial (que deixou de ser de tipo industrial para tornar-se predominantemente financeiro)."

Essa questão merece a atenção de diferentes autores que consideram estes e outros motivos que levaram a uma quebra do padrão de desenvolvimento anterior, estabelecendo-se a partir desta conjuntura uma mudança na ordem produtiva cuja principal característica estava no modelo tecnológico e nas relações entre o capital e 0 trabalho. A este respeito, Hirata (1998) considera que houve uma dupla transformação do trabalho: um processo mais concentrado nos países capitalistas centrais e nas grandes empresas industriais que exigiam estabilização do sujeito no processo de trabalho para a realização de atividades que requerem autonomia, iniciativa, responsabilidade, comunicação, e intercompreensão; enquanto nos outros espaços perdurou a instabilidade e a precarização dos laços empregatícios, "com o aumento do desemprego prolongado, e do trabalho precário, associados à flexibilidade no uso da mão de obra um movimento macro-social e mundializado." (HIRATA, 1998, p. 8).

Pochmann (1998, p. 20), por sua vez, considera essa conjuntura como um quadro geral de "fogo cruzado" contra o trabalho que ocorreu no final de século, com a mundialização das economias (Globalização) no curso das políticas neoliberais. Tratouse de uma atuação contrária à produção e ao trabalho, alcançada através de medidas de desregulamentação do mercado de trabalho, mediante a flexibilização dos contratos de trabalho, políticas governamentais favoráveis à valorização financeira do capital, e medidas deflacionistas de preços e de redução do papel do Estado.

Antunes (2011, p. 128) situa mais adiante as mutações que têm afetado muito profundamente o mundo do trabalho, entendendo que "na fábrica da flexibilidade, as novas técnicas de "gestão de pessoas", as "colaborações", e as "parcerias" procuram envolver certas personificações do trabalho de modo mais interiorizado, convertendo-as em uma espécie de autocontroladores de sua produção". Lima (2007, p. 76) também aponta para uma inevitável necessidade de inserção das empresas na lógica do mercado, tomando como exemplo um conjunto de diretrizes e estratégias empregadas entre as indústrias recuperadas, ou seja, que estavam em situação de falência e foram integradas por cooperativas organizadas, por empresas, ou por sindicatos, sob a forma de terceirização industrial. Este autor situa de modo convincente as dificuldades encontradas pelos trabalhadores na adesão a uma lógica de trabalho conjunto, cooperado, ou solidário.

Nesse contexto atual de tantas mudanças, dispor da força de trabalho pode abranger, em sentido mais amplo, não tanto a permanência, ou reinserção como empregado (vender a força de trabalho), mas a entrada ou permanência, tanto no 
trabalho autônomo, como na condição de pequeno empregador, em um mundo de trabalho heterogêneo que abriga o maior contingente de velhos trabalhadores - como os números mostraram acima.

Indicamos na sessão anterior as três categorias de atividades que mais favorecem 0 trabalho daqueles que se encontram acima de 50 anos. Primeiramente, os Militares e Funcionários Públicos, devido ao aumento dos concursos públicos ocorridos em todos os níveis de governo no período recente, o que vem sendo associado a incentivos financeiros (abonos de permanência) para que os servidores continuem na ativa. A esta estratégia se pode atribuir uma parcela do acesso de trabalhadores mais velhos ao mercado, bem como a participação mais elevada dos mesmos nas atividades econômicas em nosso país (CAMARANO, 2001; BRASIL, 2001). Em segundo lugar, os empregadores, entre os quais não só existe um significativo aumento da participação dos mais velhos, como também "foi a categoria que registrou a maior proporção de pessoas com 50 anos ou mais (33,6\%), o mesmo ocorrendo com os trabalhadores por conta própria" (IBGE, 2012).

Neste último caso, a jornada de trabalho semanal constitui um importante critério para a permanência dos mais velhos e nesse sentido os dados disponíveis indicam que uma pequena redução da carga de trabalho pode explicar essa maior participação em atividades e/ou formas de inserção - devido à possibilidade de cargas horárias menores. Os dados da Pesquisa Mensal de Emprego/PME do IBGE (2012) indicam que: "A população com 60 anos ou mais apresentou a queda mais significativa deste indicador, ou seja, o numero de horas trabalhadas".

Essa observação é válida para algumas categorias nas quais a carga semanal pode ser inferior a 40 horas, a exemplo dos trabalhadores domésticos, (38,0 horas semanais), bem como os militares e funcionários públicos (37,4 horas semanais). Já os trabalhadores por "conta própria" apresentam uma carga horária variável, abrangendo até 41,3 horas semanais em média (IBGE, 2012), sabendo-se que esta é a categoria que apresenta uma elevada participação de pessoas acima dos 50 anos.

Entretanto, sem constituir uma regra geral, certas atividades que se enquadram como "trabalho autônomo" requerem frequentemente uma extensão da jornada de trabalho, a exemplo de pequenos comerciantes e feirantes, entre os quais se encontram pessoas com mais de 70 e até 80 anos, como mostrou Guimarães (2004):

Eu me levanto quatro horas da manhã, todos os dias, cinqüenta e tantos anos de trabalho na feira, aí espero o freguês entrar, cinco horas da manhã, a gente que é feirante tem que estar antes no ponto. Esta informação pode ilustrar uma situação de carga horária variável, incorporada às próprias práticas dos feirantes e que pode ser encontrada em geral no "trabalho autônomo", porque nele é possível criar as próprias regras (GUIMARÃES, 2004, p. 299). 
Este exemplo apóia a informação estatística sobre as atividades que revelam a maior participação dos trabalhadores mais velhos. Segundo os dados indicados, são elas:

- as atividades da construção civil (pedreiros, pintores, eletricistas, hidráulicos) entre as quais a participação de pessoas mais velhas aumentou de 16,1\% (em 2002) para 22,0\% (em 2006);

- os serviços domésticos, com predominância feminina (21,0\% em 2006);

- atividades que requerem maior qualificação e são enquadradas no setor de "educação, saúde, serviços sociais, administração pública, defesa e seguridade social" que juntos representam 20,4\%, em 2006 dos idosos ocupados.

Também nesse caso, houve um crescimento acentuado, já que os dados da PME indicam que esse grupo de atividades absorvia 17,0\% dos trabalhadores mais velhos em 2002, merecendo ainda atenção o dado relativo à categoria de atividades "serviços prestados à empresa, aluguéis, atividades imobiliárias e intermediação financeira" porque compõem um grupamento com menor participação de pessoas mais velhas (14,2\% em 2002 e 14,4\% em 2006) (IBGE, 2012).

0 argumento inicial que destacamos até aqui pode ser comprovado com 0 conjunto dos dados apresentados, ou seja, a participação relativamente alta de pessoas idosas nas atividades econômicas em nosso país deve ser vista como um fenômeno que parece encobrir aspectos (positivos e negativos) merecedores de nossa atenção. Trata-se, portanto, de um duplo aspecto: uma particularidade do mercado de trabalho brasileiro, resultante da inserção do aposentado, conforme observou Camarano (2001), uma vez que no plano geral essa participação se dá entre aposentados que retornam ao trabalho e também os não aposentados - a exemplo dos que prolongam suas atividades em função dos estímulos hoje muito freqüentes, especialmente no serviço público. Mas se trata também de um prolongamento ou reingresso em certo conjunto de atividades enquadradas como "trabalho autônomo", ou ainda os pequenos empregadores - entre os quais muito frequentemente há uma precarização do trabalho e não existe uma contribuição previdenciária.

Esse dois aspectos caracterizam a População Economicamente Ativa Idosa uma PEA pura (CAMARANO, 2001) que é composta pelos idosos não-aposentados que trabalham, e uma PEA aposentada (que é composta pelos idosos aposentados que trabalham). Nesta categoria se encontram atualmente 6,49\% dos trabalhadores idosos (BRASIL, 2010, p. 103), constituindo-se em um dado a mais que permite demonstrar a existência de diferentes ordens de entraves ou estímulos à participação dos idosos no mercado de trabalho. 
No primeiro caso, encontram-se as mudanças introduzidas no mercado formal, que muitas vezes conduzem à substituição de funcionários mais velhos pelos mais jovens, alegando-se uma maior capacidade de produção destes últimos, ou a presença dos requisitos de qualificação mais adequados ao perfil do "novo trabalhador". Isso parece ser verdade em certos setores industriais de trabalho intensivo, nos quais o custo da mão-de-obra torna-se atualmente um fator muito enfatizado nos orçamentos das empresas. Em muitos casos, a lógica do mercado impõe a competitividade que é associada à capacidade de redução de custos, principalmente de mão-de-obra, o que faz crescer a terceirização e a informalidade nas relações de trabalho, a fragmentação dos serviços nas fábricas e a recorrência ao trabalho domiciliar.

A esse respeito, Cintra; Ribeiro; Andrade (2010, p. 12) observam que em alguns setores de atividades a aposentadoria manteve uma relação direta com a questão da produtividade. Os trabalhadores idosos, seja pela perda da força física, seja pelo desconhecimento ou inadaptação às novas técnicas, seriam muitas vezes preteridos e a aposentadoria surge como uma forma de produzir certa rotatividade da mão-de-obra no trabalho, pela troca de gerações. Ao mesmo tempo, os trabalhadores jovens ganham menos, o que estimula muitas indústrias a oferecerem indenizações e recompensas financeiras aos trabalhadores mais velhos, estimulando a aposentadoria.

Em estudo de caso realizado no setor calçadista entre empresas localizadas na cidade de Franca, São Paulo, Cintra; Ribeiro; Andrade (2010) observaram significativa quantidade de aposentados que trabalhavam em bancas de pesponto dos calçados, situadas em uma parte separada das residências, muitas vezes em dois cômodos que abrigavam até dez máquinas e até quinze funcionários, sendo todos registrados. A atividade de costura manual de calçados era realizada no interior das residências, não havendo divisão entre local de trabalho e de moradia e predominando o trabalho nas salas e varandas, com condições positivas de iluminação e a ventilação. 0 motivo indicado para a continuação do trabalho entre os idosos foi a dificuldade financeira, devido ao baixo valor das aposentadorias como operários, confirmando as condições de trabalho da maior parte dos autônomos, terceirizados e informais. No entanto os pesquisadores revelam que em momento algum os entrevistados demonstraram sentimentos de inutilidade, dependência, ou questões negativas perante a situação de aposentadoria, por se considerarem inseridos socialmente (CINTRA; RIBEIRO; ANDRADE, 2010).

Em outro estudo de caso realizado no setor calçadista com empresas localizadas na cidade de Ipirá, na Bahia, Silva (2008, p. 128) constata que a partir da reestruturação produtiva o setor calçadista passou a empregar mais os jovens, e admite que "parece que este perfil é mais marcante no Nordeste, aonde vem ocorrendo investimentos nesse ramo". Segundo a autora, trata-se de grande empresa de calçados que empregava, entre 2005-2006, cerca de 1733 trabalhadores, dos quais apenas 19 homens e 13 mulheres 
tinham mais de 40 anos de idade, o que era justificado não apenas pela razões conhecidas de agilidade e condições físicas, mas também pelo fato dos jovens serem menos exigentes e terem "menos vícios de outras empresas" (SILVA, 2008, p. 130). Entretanto, em razão da tradição artesanal em couro ser presente em cidades nordestinas, como é o caso do estabelecimento das modernas fábricas de calçados em 11 cidades baianas, desde o ano de 1997, na cidade de Ipirá, o artesanato em couro proporcionou um significativo crescimento da produção de carteiras de cédulas, além de bolsas e cintos, nas quais se observa a participação dos trabalhadores mais velhos, especialmente em curtumes e pequenas produções de carteiras de cédulas (SILVA, 2008, p. 99).

Fora a indústria, a alternativa para a maioria é o trabalho informal e autônomo, uma vez que as pessoas mais velhas enfrentariam mais dificuldades em aprender e utilizar as novas tecnologias, além de enfrentar os desafios da aposentadoria, e a insuficiência de renda para a própria manutenção e da família. Diante disso, tendem a submeter-se ao subemprego, ao trabalho informal, como solução geralmente relacionada com ocupações precárias e salários baixos. A esse respeito, Silva e Barbosa (2001) constataram que no Rio de Janeiro dois terços da mão-de-obra informal é formada por homens entre 25 e 59 anos, dos quais a metade se encontra na faixa dos 40 anos ou mais. A partir dessa estatística, dois aspectos podem ser considerados: primeiro, a idade como limite para a permanência prolongada no setor formal; segundo, a experiência profissional como produtora de novos caminhos ou meios autônomos para se completar a renda (GUIMARÃES, 2004).

Se os motivos que levam ao prolongamento da vida produtiva e à permanência dos mais velhos no trabalho podem ser muitas vezes semelhantes - seja como responsável pela família ou domicílio, seja por opção individual, pelo desejo de manter uma atividade produtiva - são diferentes, no entanto, as oportunidades de trabalho por eles encontradas. Torna-se, então, importante conhecer as condições de trabalho prevalecentes em função da classe social na qual os indivíduos se situam, já que o fato de viver e trabalhar na cidade, exercendo atividades informais, de baixa renda, por um longo período, corresponde a uma situação social específica. (GUIMARÃES, 2004, p. 389).

Segundo o estudo do IBGE, A Economia Informal Urbana (1997), as razões da permanência nas atividades classificadas como trabalho autônomo, ou informal são: a busca pela independência, o desejo de escapar do controle de um patrão e a melhoria dos rendimentos - fatores que são convergentes com a situação de dispor do próprio trabalho, como estamos argumentando. Além desses, dois outros fatores são igualmente importantes: 0 peso da tradição familiar e da experiência profissional adquirida. Em estudo de caso realizado em Salvador, Guimarães (2004, p. 393) mostrou que os trabalhadores informais nessa cidade exercem suas atividades sozinhos ou com 
familiares e sócios, e são, predominantemente, trabalhadores mais velhos, com maiores chances de inserção nessas atividades.

Assim, o fator idade tende a aumentar as chances de os indivíduos serem bem sucedidos como trabalhadores autônomos com destaque para o papel exercido pela família - ser um chefe provedor mais velho, ocupado como autônomo, responsável pela manutenção de membros não ativos (filhos ou agregados sem ocupação). A título de exemplo, na geração dos ambulantes que se encontrava acima dos 60 anos, a forma de atividade mais freqüente era também a iniciativa própria, a reinserção ocupacional, ou o retorno ao mercado de trabalho através do início de um pequeno negócio. Segundo alguns relatos: "Depois de ser ajudante de encanador na construção civil, resolvi sair e tentar a vida como autônomo"; "Quando saí da loja X, ouvi conselhos e fui começando a comprar alguma mercadoria para revender"; "Me aposentei de uma industria e passei a comprar alguma coisa para vender.” (GUIMARÃES, 2004, p. 397).

\section{OS ENTRAVES E ESTÍMULOS AOS TRABALHADORES MAIS VELHOS}

Para prosseguir neste enfoque, consideramos a perspectiva de Bourdieu (1994, p. 14) de empreender-se "uma montagem discursiva que permite justapor a tabela estatística, a fotografia, o resumo de uma entrevista, a reprodução do documento e a linguagem abstrata da análise (fazendo...) com que coexistam o mais abstrato e o mais concreto". Essa argumentação nos permite passar ao universo dos dados qualitativos com a pretensão de abordar sob outro plano, a perspectiva dos agentes. Retomamos, portanto, o argumento inicial de que permanecer ou retornar ao trabalho após os 60 anos pressupõe que se está em condições de dispor da força de trabalho, entendida nesse plano geral, tanto no nível das condições de saúde física e mental, como no nível das disposições práticas (BOURDIEU, 1994, p. 18) que incluem o trabalho, e a família, sabendo-se, por exemplo, que a maior parte daqueles que permanecem, o fazem como contribuição familiar e manutenção do domicílio.

Os fatores determinantes e merecedores de atenção que estamos enfatizando aqui, dizem respeito à oferta da força de trabalho, aos atributos considerados sociais dessa oferta (OFFE, 1989), especialmente a idade e sexo e suas relações com as dimensões mais subjetivas dos agentes sociais. Devido aos próprios limites da legislação trabalhista, um dos focos mais freqüentes encontrados nos estudos relativos ao tema do trabalho dos idosos diz respeito à relação de conflito entre continuidade e ruptura do período laboral, representado pelo momento da aposentadoria, desde que o trabalho e a produção são tidos como valores fundamentais nas diferentes sociedades. Assim, a aposentadoria pode ser percebida como perda - do próprio significado da vida, de um ponto de referência, de sua organização. Isso ocorre, segundo Selig e Valore (2010, p. 59) 
[...] na medida em que o trabalho determina horários, atividades, relacionamentos, status e reconhecimento social, padrão de vida, relações com o tempo livre, em especial, a perda de um papel que, por muito tempo, fez parte da imagem e da definição do indivíduo.

Em função da rotina, do ritmo de vida decorrente dos horários de trabalho, muitas vezes a aposentadoria pode conduzir até mesmo a uma predisposição à doença (SELIG; VALORE, 2010, p. 5-9). Frequentemente, as representações sobre esse tipo de conflito, vão desde a compreensão de que "o mais feliz da aposentadoria é você estar disponível para qualquer coisa, até para não fazer nada"; até a compreensão de que "aposentado não é um inválido, aposentado não pára"; e mais ainda, "manter a atividade é sinônimo de manter-se viva, pois se a pessoa é sozinha e pára de trabalhar pode morrer logo; morrer é não poder ver e não poder ser vista." (SELIG; VALORE, 2010, p. 12).

Entretanto, é possível admitir que tudo isso depende do que se fazia, e o momento da aposentadoria também pode representar uma ruptura em relação a um ambiente estressante, competitivo, opressor. Nesse caso, a aposentadoria pode representar: "A coisa mais feliz que pode acontecer, a maior tranqüilidade, acho que vai ser, é fazer nada 0 dia inteiro, fazer coisas só pra mim" (SELIG; VALORE, 2010, p. 7). Em muitos casos, a própria noção de uso do tempo tende a mudar, diante do "medo de não poder usufruir 0 tempo que resta"; "a idéia de que se precisa aproveitar a vida antes de estar velha, como se estivesse postergando o "viver a vida" para depois da aposentadoria (SELIG; VALORE, 2010, p. 7).

Em função do primeiro ponto - a valorização da permanência no trabalho compreende-se como este se torna importante na última fase da vida, tornando plausível considerar que alguns idosos estão dispostos ao desafio do novo, o que vem levando alguns empresários a oferecerem oportunidades no mercado de trabalho para os mais velhos, valorizando e destacando características como responsabilidade, organização, disciplina, e pontualidade nas atividades realizadas. Isso faz com que eles retornem ao mercado de trabalho, não apenas por uma necessidade, mas, sim, "por vontade própria, de se sentir útil, entendendo-se que a sociedade como um todo deve se preparar para envelhecer com dignidade e receber a nova leva de idosos." (SANTOS et al., 2007, p. 5).

Reintroduzimos aqui um contexto atual de mudanças, no qual dispor da força de trabalho pode abranger, em sentido mais amplo, abrir um negócio, poder realizar um velho sonho, e principalmente, manter a atividade sem ter patrão. A entrada ou permanência no trabalho autônomo abrange um mundo heterogêneo que, segundo já demonstramos, abriga o maior contingente de velhos trabalhadores, convergindo com a tendência observada na atualidade, de prolongar a vida "produtiva" ao máximo, tanto 
aumentando-se a idade para aposentadoria compulsória, como dando-se incentivos abonos de permanência - para aqueles que podem se aposentar, fazendo com que optem por continuar no mesmo trabalho.

Como opção, ou como necessidade, a crescente participação do idoso no mercado de trabalho se daria por motivos comportamentais ou puramente econômicos, mas em qualquer caso, já provoca mudanças profundas na vida da população idosa. Santos et al. (2007, p. 5) argumentam que muitas vezes por necessidade, o idoso sai à procura de emprego, seja para complementar sua renda juntamente à sua aposentadoria, ou para buscar uma nova renda. Entendemos que nestes casos, é preciso ter em vista as diferenças de classe social e nível de renda, e observar-se diferentes escalas de opções e escolhas nesse campo, como se pode depreender do exemplo de um empacotador no supermercado Pão de Açúcar, Pinheiros, São Paulo, que diz "trabalhar porque gosta e para complementar a renda, porque a aposentadoria é pequena; depois que comecei a trabalhar nunca faltou dinheiro em casa". Neste exemplo, o trabalho é visto como um bom passatempo na vida de um idoso que vive sozinho, mas segundo o idoso entrevistado "minha agenda está lotada." (SANTOS et al., 2007, p. 10).

0 trabalho por opção, como um passatempo, ou como uma realização do passado, indica uma situação mais freqüente entre as classes médias, tal como se observou em reportagem recente na qual se constata que o aumento da expectativa de vida modifica o perfil de profissionais na pós-aposentadoria: "o educador financeiro Mauro Calil, de 70 anos, revela como permanece em forma e ativo na profissão; 0 consultor Luiz Affonso Romano ressalta que os investimentos são necessários ao longo da vida inteira e não apenas na aposentadoria" (ABRANCHES, 2012).

Em outras situações, atribui-se o trabalho do idoso a "uma tentativa de fugir do estigma da inatividade e manterem-se ocupados e produtivos, simplesmente preenchendo o vazio deixado pelo não-trabalho, continuando a fazer as mesmas coisas (às vezes até 0 mesmo trabalho) sem considerar a possibilidade de novas escolhas, inclusive a do não trabalho (SELIG; VALORE, 2010, p. 2). Para as autoras citadas,

[...] é como se o gosto pela agitação, pelo movimento, pelo contato social constante fosse 0 melhor jeito de viver, significando que não viver assim, não seria uma escolha, uma preferência, mas resultado de uma 'anomalia' existencial ou velhice (SELIG; VALORE, 2010, p. 13).

Esse não parece ser o caso dos "trabalhadores autônomos", a exemplo dos velhos trabalhadores focalizados por Guimarães (2004, p. 403): um vendedor ambulante e um feirante, respectivamente, com 73 e 85 anos de idade que indicam os tipos de estratégias de trabalho e de vida que configuram um modo específico de permanência e prolongamento da vida produtiva. Estas estratégias correspondem, em ambos os casos, a 
formas de reinserção ocupacional, uma vez que se aposentaram e reingressaram no mercado de trabalho através de atividades consideradas informais, que tendem a favorecer a atuação de pessoas mais velhas, como buscamos demonstrar ao longo da presente análise. Acreditamos que se existe um lado positivo nos personagens acima destacados, ele transparece na sua capacidade (disposição) de trabalho e na competência para criar os seus mecanismos de sobrevivência - "sempre procurar criar alguma coisa" (GUIMARÃES, 2004, p. 403).

\section{CONCLUSÃo}

Ao longo da presente análise defendemos o argumento de que permanecer ou retornar ao trabalho após os 60 anos pressupõe que se está em condições de dispor da força de trabalho, tanto no nível das condições de saúde física e mental, como no nível das disposições práticas que incluem o trabalho, a família, a sociabilidade. Dispor da força de trabalho pode abranger, não tanto a permanência, ou reinserção como empregado (vender a força de trabalho), mas a entrada ou permanência como trabalhador autônomo, ou como pequeno empregador, que consistem em um mundo heterogêneo e que desde sempre tem constituído o maior espaço para os trabalhadores mais velhos no mercado de trabalho (PRANDI, 1980).

Essa questão central que buscamos desenvolver aqui nos permite compreender até que ponto o prolongamento da vida ativa pareceria contrariar à tão esperada fase do descanso, da aposentadoria, ao tempo em que pode mesmo contribuir para dar um novo rumo ao trabalhador da terceira idade (SANTOS et al., 2007). Examinamos alguns aspectos do processo de envelhecimento populacional e de alguns fatores que caracterizam a última fase da vida, considerando o ponto de vista da oferta de força de trabalho e os lugares no mercado de trabalho atual que absorvem os trabalhadores mais velhos, sua busca por oportunidades, sua capacidade de se atualizar e se manter nas atividades já exercidas.

Concluímos que seja como opção, ou como necessidade, a convergência entre 0 prolongamento do tempo de vida, como fator tão importante que marca a contemporaneidade, e o prolongamento da atividade produtiva, representa hoje uma realidade que passa a fazer parte dos planos individuais, e de certos recursos das empresas e do mundo dos negócios. 0 outro lado desse prolongamento parece estar presente na principal característica das atividades aqui focalizadas - a ausência das garantias trabalhistas - uma vez que nas atividades ligadas ao pequeno comercio, ou à prestação de serviços, enquadradas, de um modo geral, no que se convencionou chamar de "trabalho autônomo", existe a "irregularidade que ganha estabilidade" e que encobre o crescimento do trabalho precário, muitas vezes realizado em condições inadequadas. 


\section{REFERÊNCIAS}

ANTUNES, Ricardo. Os exercícios da subjetividade: as reificações inocentes e as reificações estranhadas. Caderno CRH, Salvador, v. 24, n. 1, p. 121-131, 2011.

BOURDIEU, Pierre. Espaço social e espaço simbólico. In: . Razões práticas: sobre a teoria da ação. Papirus, 1994. p. 13-34.

BRASIL. Ministério do Trabalho e Emprego. Departamento Intersindical de Estatísticas e Estudos Sócio-Econômicos - DIEESE. A situação do trabalho no Brasil. São Paulo: DIEESE, 2001.

. Departamento Intersindical de Estatísticas e Estudos Sócio-Econômicos DIEESE. Anuário dos trabalhadores. São Paulo: DIEESE. Disponível em: <http://www.dieese.org.br/anu/AnuTrab2010/Arquivos/ANUARI0_TRABALHADORES,20 10_2011v.pdf>. Acesso em: 2 ago. 2012.

BRUSCHINI, Cristina. Gênero e trabalho no Brasil: novas conquistas ou persistência da discriminação? In: ROCHA, Maria Isabel (Org.). Trabalho e gênero, mudanças e permanências. São Paulo: Ed. 34, 2000. p. 13-58.

CAMARANO, Ana Amélia. 0 idoso brasileiro no mercado de trabalho. Mercado de trabalho: conjuntura e analise. 2001. Disponível em:

<http://www.ipea.gov.br/pub/bcmt/mt_012h.pdf>. Acesso em: 20 jun. 2010.

CAMARANO, Ana Amélia; MEDEIROS, M. Introdução. In: CAMARANO, Ana Amélia (Org.). Muito além dos 60: os novos idosos brasileiros. Rio de Janeiro: IPEA, 1999. p. 118.

CINTRA, Thais Silva; RIBEIR0, Daniela de Figueiredo; ANDRADE, Antônio dos Santos. 0 cotidiano de aposentados que continuam trabalhando de maneira informal na indústria calçadista: percepções sobre a aposentadoria e o trabalho atual. Cadernos de Psicologia Social do Trabalho, São Paulo, v. 13, n. 2, p. 277-287, set. 2010.

GUIMARÃES, Iracema. Maturidade e experiência em atividades informais de baixa renda. Caderno CRH, Salvador, v. 17, n. 42, p. 389-404, set./dez. 2004.

HIRATA, Helena. Reestruturação produtiva, trabalho e relações de gênero. Revista Latinoamericana de Estudos del Trabajo, São Paulo, ano 4, n. 7, p. 5-27, 1998.

IBGE. Pesquisa mensal de emprego e desemprego: o trabalho a partir dos 50 anos de idade. Disponível em:

$<$ www.ibge.gov.br/home/estatistica/indicadores/trabalhoerendimento/pme_nova/defaul t.sht>. Acesso em: 20 jul. 2012. 
. Sinopse do censo demográfico de 2010. Disponível em:

$<$ http://www.ibge.gov.br/home/estatistica/populacao/censo2010/sinopse/default_sinops e.shtm>. Acesso em: 27 jun. 2012.

. Tábuas completas de mortalidade 2009. Disponível em:

$<$ http://www.ibge.gov.br/home/presidencia/noticias/noticia_visualiza.php?id_noticia= 1767\&id_pagina=1>. Acesso em: 16 out. 2012.

ABRANCHES, Guto. Aumento da expectativa de vida modifica perfil de profissionais na "pós-aposentadoria". Jornal Conta Corrente, 2012. Disponível em: $<$ http://g1.globo.com/globo-news/conta-corrente/videos/t/conta-casual/v/aumento-daexpectativa-de-vida-modifica-perfil-de-profissionais-na-pos-aposentadoria/2062393/>. Acesso em: 27 jul. 2012.

LIMA, Jacob. 0 trabalho em cooperativas: dilemas e perspectivas. In: DRUCK, Graça; FRANCO, Tânia (Org.). A perda da razão social do trabalbo, terceirização e precarização. São Paulo: Boitempo, 2007. p. 77-107.

MATTOSO, Jorge Eduardo. Trabalho sob fogo cruzado. São Paulo em Perspectiva, São Paulo, v. 8, n. 1, p. 13-21, 1994.

OFFE, Claus. Economia social do mercado de trabalho. In: Trabalho \& sociedade. Rio de Janeiro: Tempo Brasileiro, 1989. p. 41-81.

POCHMANN, Marcio. A desestruturação do mercado de trabalho brasileiro nos anos 90: uma análise regional. Campinas: Instituto de Economia, 1998. p. 1-24.

PRANDI, José Reginaldo. Trabalhadores por conta própria em Salvador. In: Vilmar Faria. (Org.). Babia de todos os pobres. São Paulo: Vozes, 1980. p. 129-133.

QUEIROZ, Bernardo et al. Envelhecimento populacional e os sistemas públicos de suporte aos idosos: o caso brasileiro. In: VAITSMAN, Jeni; PAES-SOUZA, Rômulo (Org.). Avaliação de políticas e programas do MDS: resultados. Brasília: MDS, 2007. p. 343369. v. 2.

SANTOS, Camila Tais Moura et al. 0 idoso e o mercado de trabalho. 2007. Trabalho (Disciplina de Administração) - Faculdade Novos Horizontes, Belo Horizonte. Disponível em:

$<$ http://www.unihorizontes.br/pi/pi_cba_2_2007/adm/idoso_no_mercado_de_trabalh o.pdf>. Acesso em: 16 out. 2012.

SELIG, Gabrielle Ana; VALORE, Luciana Albanese. Imagens da aposentadoria no discurso de pré-aposentados: subsídios para a orientação profissional. Cadernos de Psicologia Social do Trabalho, São Paulo, v. 13, n. 1, p. 73-87, 2010. 
SILVA, Jailson de Souza; BARBOSA, Jorge Luiz. O sentido do trabalho informal na construção de alternativas socioeconômicas e o seu perfil no Rio de Janeiro. Rio de Janeiro: Instituto de Estudos do Trabalho e Sociedade, 2001.

SILVA, Zilmar. Divisão etária e sexual do trabalho, o sexo e a idade na dinâmica do capital flexível numa unidade produtiva de calçado de Ipirá-BA. 2008. Dissertação (Mestrado em Estudos Interdiciplinares Sobre Mulheres, Gênero e Feminismo) Programa de Pós-Graduação em Ciências Sociais, Universidade Federal da Bahia, Salvador. 